\section{Ecturs}

- An additional appendix is published online only. To view this file please visit the journa online (http://thorax.bmj.com/ content/67/3.toc)

${ }^{1}$ Centre for Workplace Health, Sheffield, UK

${ }^{2}$ University of Birmingham,

Birmingham, UK

${ }^{3}$ North West Lung Centre,

Manchester, UK

${ }^{4}$ Heartlands Hospital,

Birmingham, UK

${ }^{5}$ Oueen's Medical Centre,

Nottingham, UK

${ }^{6}$ Royal Brompton Hospital,

London, UK

${ }^{7}$ General Practice Research Unit,

Manchester, UK

${ }^{8}$ Royal Victoria Infirmary,

Newcastle upon Tyne, UK

${ }^{9}$ North Manchester General

Hospital, UK

${ }^{10}$ Centre for Workplace Health,

Buxton, UK

${ }^{11}$ Western General Hospital

Edinburgh, UK

${ }^{12}$ Aintree Chest Centre,

University Hospital Aintree,

Liverpool, UK

${ }^{13}$ British Occupational Health

Research Foundation, Society of

Occupational Medicine and

Faculty of Occupational

Medicine, London, UK

\section{Correspondence to}

Professor D Fishwick, Centre for Workplace Health, Respiratory

Function Unit, A Floor, Royal

Hallamshire Hospital, Glossop

Road, Sheffield S10 2JF, UK;

d.fishwick@sheffield.ac.uk

Received 6 July 2011

Accepted 18 November 2011

Published Online First

9 December 2011

GUIDELINES UPDATE

\title{
Standards of care for occupational asthma: an update
}

\author{
David Fishwick, ${ }^{1}$ Christopher Michael Barber, ${ }^{1}$ Lisa M Bradshaw, ${ }^{1}$ Jon G Ayres, ${ }^{2}$ \\ Richard Barraclough, ${ }^{3}$ Sherwood Burge, ${ }^{4}$ Jonathan M Corne, ${ }^{5}$ Paul Cullinan, ${ }^{6}$ \\ Timothy Laszlo Frank, ${ }^{7}$ David Hendrick, ${ }^{8}$ Jennifer Hoyle, ${ }^{9}$ Andrew D Curran, ${ }^{10}$ \\ Robert Niven, ${ }^{3}$ Tony Pickering, ${ }^{3}$ Peter Reid, ${ }^{11}$ Alastair Robertson, ${ }^{4}$ Chris Stenton, \\ Christopher J Warburton, ${ }^{12}$ Paul J Nicholson ${ }^{13}$
}

\section{ABSTRACT}

Background The British Thoracic Society (BTS)

Standards of Care (SoC) Committee produced a standard of care for occupational asthma (OA) in 2008, based on a systematic evidence review performed in 2004 by the British Occupational Health Research Foundation (BOHRF).

Methods BOHRF updated the evidence base from 2004-2009 in 2010.

Results This article summarises the changes in evidence and is aimed at physicians, nurses and other healthcare professionals in primary and secondary care, occupational health and public health and at employers, workers and their health, safety and other representatives.

Conclusions Various recommendations and evidence ratings have changed in the management of asthma that may have an occupational cause.

\section{BACKGROUND}

The British Thoracic Society (BTS) Standards of Care (SoC) Committee produced a standard of care for occupational asthma (OA) in $2008,{ }^{1}$ based on a systematic evidence review performed in 2004 by the British Occupational Health Research Foundation (BOHRF). ${ }^{2}$ BOHRF updated the evidence base from 2004 to 2009 in $2010 .^{3}$

This article summarises the changes in evidence and is aimed at physicians, nurses and other healthcare professionals in primary and secondary care, occupational health and public health, and at employers, workers and their health, safety and other representatives.

\section{STANDARD OF CARE UPDATE}

It is not intended, nor should it be taken to imply, that these amendments to the SoC override existing legal obligations, for example the Health and Safety at Work Act 1974, the Management of Health and Safety at Work Regulations 1999, the Equality Act 2010, the Control of Substances Hazardous to Health Regulations 2002 and other relevant legislation.

\section{General comments}

The recent evidence supports the estimate that occupational factors account for one in six cases of adult asthma. The range of incidence for cases of OA has been upwardly revised to between 12 and 300 cases/million workers/year. Under-identification of OA persists. ${ }^{4}$
All the following statements are referenced to the 2010 BOHRF review, ${ }^{3}$ as details of the evidence review update, full references to statements in this document, an audit tool and case management can be found in the associated online supplement.

\section{Prevention and health surveillance}

Further evidence supports the role of health surveillance for identifying $\mathrm{OA}$ at an earlier stage, although screening questionnaires have significant false-negative response rates. Developing a workplace culture that supports workers to report symptoms accurately is key, as is workers' knowledge of a plan of action were they to report various work-related respiratory complaints.

Forced expiratory volume in $1 \mathrm{~s}\left(\mathrm{FEV}_{1}\right)$ and forced vital capacity (FVC) measured to screen for OA are likely to detect few cases that would not otherwise be detected by respiratory questionnaire alone.

\section{Education}

All workers exposed to asthmagens should be warned about relevant symptoms potentially attributable to exposure, how agents in the workplace can affect health, and how best to avoid problems. Workers should be informed what to do, and in particular to whom they should report, if they develop relevant symptoms, particularly if these occur between health surveillance visits.

Educational programmes should be aimed at employers and healthcare professionals, including nurses and doctors (based in industry, primary and secondary care), occupational hygienists, and workers.

\section{Diagnostic process}

Health practitioners who suspect a worker of having OA should make an early referral to a physician with expertise in OA.

All those involved in the potential identification of OA have an obligation to minimise delays.

\section{Medical history}

The latest evidence supports the importance of nasal symptoms in addition to asthma symptoms. Specifically, rhino-conjunctivitis may precede or coincide with the onset of $\mathrm{OA}$, and the risk of $\mathrm{OA}$ development is highest in the year following the onset of rhino-conjunctivitis.

\section{Occupational history}

Hairdressers have been added to the list of workers with OA most commonly reported to schemes. 
Data from recent population studies also identify that cooks, healthcare workers, woodworkers and mechanics are also at greater risk of reporting asthma. The most frequently reported agents causing OA have been expanded to include adhesives, metals, resins in addition to isocyanates, flour and grain dust, colophony and fluxes, latex, animals, aldehydes and wood dust.

The full list of most commonly reported agents, workers and jobs from population-based studies with elevated OA risks are given in table 2 in the online appendix.

\section{Investigations \\ Lung function}

All suspected cases of OA should undergo $\mathrm{FEV}_{1}$ and FVC measurement according to agreed criteria, and the results compared with a predicted value and previous results if available.

Pre-shift to post-shift changes in lung function have high specificity but only low sensitivity for OA. If these changes are present, they may support a diagnosis, but they are frequently absent in people subsequently confirmed to have $\mathrm{OA}$. It is recommended that pre-shift and post-shift $\mathrm{FEV}_{1}$ changes are only used in conjunction with other diagnostic approaches.

There is a considerable evidence base for the use of serial peak expiratory flow (PEF) measurements to investigate workers when $\mathrm{OA}$ is suspected. With appropriate training and explanation, it is possible to achieve high-quality recordings in these workers. While these tests may be susceptible to falsification and transcription errors, they offer the best and easiest first-line approach to assessing physiological response to asthmagens at work. High-quality recordings can be obtained for over $70 \%$ of patients.

Serial PEF should be recorded at least four times a day for at least three continuous weeks. Recordings for shorter durations are of lower diagnostic value. It is best to aim for readings every $2 \mathrm{~h}$, so that practically at least four good measures per day will be achieved. Suitable record forms can be downloaded from http://www.occupationalasthma.com or http://www.scottishshield.org. Ideally, inhaled steroids should be withheld until the series is completed or required doses kept constant and as low as possible.

If the person is currently not exposed at work, serial PEF can be measured during a 2 -week 'run in' period, followed by a return to work. All recordings should be entered onto a computer for analysis using suitable software. Computer-based analyses of PEF may be helpful in the diagnosis of OA. At least one software program calculates a work-effect index from discriminant analysis based on pattern recognition. Such analysis allows charts to be graded positive, equivocal or negative for a diagnosis of $\mathrm{OA}$. A positive chart has a quoted sensitivity of approximately $75 \%$ and a specificity of $95 \%$ for a diagnosis of $\mathrm{OA}$, although these estimates are quality dependent, and pooled estimates suggest $64 \%$ sensitivity (95\% CI $43 \%$ to $80 \%$ ) and a specificity of $77 \%$ (95\% CI $67 \%$ to $85 \%) .{ }^{5}$ It is important to note that PEF charts do not confirm a specific cause, nor do they distinguish OA from work-aggravated asthma. Any problems with interpretation of serial PEF charts should be referred to a specialist centre.

\section{Immunological testing}

New evidence supports skin prick and serological testing as sensitive for detecting specific $\operatorname{IgE}$ caused by most high molecular weight agents, but these tests are not specific for diagnosing asthma or OA. Skin prick and serological tests are less sensitive for detecting specific $\operatorname{IgE}$ and $\mathrm{OA}$ caused by low molecular weight agents and while specificity may be higher they are not specific for diagnosing $\mathrm{OA}$.

\section{Non-specific bronchial responsiveness}

While assessment of non-specific bronchial responsiveness is a useful diagnostic investigation, single and serial measures have only moderate specificity and sensitivity for the validation of $O A$.

\section{Specific broncho-provocation testing}

Comments relating to specific broncho-provocation testing remain unchanged. These tests should be performed only in specialised (tertiary) centres. A positive test identifies the cause of $O A$, provided exposures received are equivalent to those in the workplace. Negative tests do not necessarily exclude OA, as the challenge may not adequately reproduce exposures at work. Exposure received during SBPT should be measured if practical.

Alternatively, workplace challenge may be used (a variation of serial PEF or serial $\mathrm{FEV}_{1}$ measurements). This usually involves frequent monitoring of $\mathrm{FEV}_{1}$ or PEF on multiple days of work, during and between periods of exposure to the suspected agents. One way of approaching this type of challenge is to take data from non-exposed days to calculate a mean and 95\% CI of the 'expected' $\mathrm{FEV}_{1}$ at each time point. These are compared with $\mathrm{FEV}_{1}$ values measured on exposed days.

\section{Other tests}

Newer techniques are available to investigate potential cases of $\mathrm{OA}$. The role of fractional exhaled nitric oxide measurements in the diagnosis of $\mathrm{OA}$ has not been established. A normal value does not exclude a diagnosis of OA.

With regard to sputum eosinophilia for the diagnosis of $O A$, such measurements may be helpful in the diagnosis of OA, although the absence of sputum eosinophilia does not exclude a diagnosis of $O A$.

\section{Management \\ Medical management}

The pharmacological management of $\mathrm{OA}$ does not differ from the management of asthma that is not work related (summarised by the BTS at http://www.brit-thoracic.org. $\mathrm{uk} /$ ). Once a diagnosis of $\mathrm{OA}$ is confirmed, the patient should be advised (preferably verbally and in writing) that the prognosis is improved by early and complete removal from exposure.

Symptoms and functional impairment associated with $\mathrm{OA}$ may persist for many years after avoidance of further exposure to the causative agent. Evidence supports the view that OA may become a chronic condition, similar to non-OA, and may require similar prolonged medical management.

Patients with confirmed or possible OA should be followed up at a specialist centre while risks of continuing exposure to allergen remain. The recommended follow-up is every 3 months for 1 year, and then every 6 months thereafter.

Patients with confirmed OA who have left work, or who have no ongoing asthmagen exposure risk, should be followed up for a minimum of 3 years at a specialist centre.

Communicating with the workplace is useful, but requires the patient's written consent. Patients should be informed of the possible adverse health effects of continuing exposure to themselves and to co-workers should they not permit necessary workplace investigations.

Acknowledgements The authors would like to acknowledge the British Occupational Health Research Foundation, and the assistance of Professor Sir Anthony Newman Taylor. 


\section{Competing interests None.}

Contributors All authors significantly contributed to the formulation of the standard of care given the recent evidence-based review, and all were involved in writing and developing the document.

Provenance and peer review Not commissioned; externally peer reviewed.

\section{REFERENCES}

1. Fishwick D, Barber CM, Bradshaw LM, et al; British Thoracic Society Standards of Care Subcommittee Guidelines on Occupational Asthma. Standards of care for occupational asthma. Thorax 2008;63:240-50.
2. Nicholson PJ, Cullinan P, Newman Taylor AJ, et al. Evidence based guidelines for the prevention, identification, and management of occupational asthma. Occup Environ Med 2005;62:290-9.

3. Occupational Asthma-Identification, Management and Prevention: Evidence Based Review and Guidelines. British Occupational Health Research Foundation, 2010. ISBN 978-0-9564979-1-8. http://www.bohrf.org.uk/downloads/OccupationalAsthma EvidenceReview-Mar2010.pdf (accessed 20 Sep 2011).

4. Orriols R, Costa R, Albanell $\mathrm{M}$, et al. Reported occupational respiratory diseases in Catalonia. Occup Environ Med 2006;63:255-60.

5. Tarlo SM, Balmes J, Balkissoon R, et al. Diagnosis and management of work-related asthma: American College of Chest Physicians Consensus Statement. Chest 2008; 134(Suppl 3):1S-41.

\section{Pulmonary puzzles}

\section{ANSWER}

From the question on page 273

Lymphomatoid granulomatosis (LYG) grade 1 was diagnosed. LYG is a rare T-cell rich, Epstein-Barr virus (EBV)-associated, B-cell lymphoproliferative disorder. Lung involvement is the predominant feature but extrapulmonary manifestations occur, especially skin and nervous system involvement such as optic neuritis. ${ }^{1} 2$ Systemic symptoms and lymphopenia are also described. Lung Involvement in LYG may be unilateral or bilateral and includes interstitial and alveolar compartments of the lung. The most common radiographic findings are multiple nodular opacities and masses with poorly defined margins distributed along the peribronchovascular bundle or interlobular septa. ${ }^{3}$ Reticular opacities associated with nodules, mediastinal lymphadenopathy and large conglomerate masses with air bronchograms are also observed. ${ }^{3}$

Histologic and immunohistochemical features are crucial for LYG diagnosis: mixed mononuclear cell infiltrate containing CD20-positive large B lymphocytes and numerous CD3-positive small lymphocytes, vascular infiltration, necrosis, and evidence of EBV infection. ${ }^{1}$ Positivity for EBV infection in histological specimens ranges from 57 to $100 \%$ and therefore its absence does not rule out the diagnosis in proper clinical, radiological and histological scenarios, as was the case for our patient. ${ }^{14}$

Grade 1 LYG contains only a few large B cells whereas numerous large $B$ cells are present in grade 3 disease, which means worse prognosis. Current knowledge about LYG tends to categorise grades 2 and 3 as lymphomas, considering the frequent presence of monomorphous foci of atypical B cells and the clinical behaviour. ${ }^{15}$

The treatment of LYG is not well established. There has been a tendency to treat higher grade LYG with chemotherapy regimens for lymphomas but the treatment for grade 1 LYG is less clear. ${ }^{1}$ There are some reports of spontaneous resolution and treatment success with interferon alfa- $2 b$, corticosteroids, cyclophosphamide, and bone marrow transplant. Our patient was treated with corticosteroids, cyclophosphamide and rituximab with complete remission of lung lesions. The optic neuritis also remitted but the patient retained significant visual impairment. The patient was placed on prednisone and oral cyclophosphamide with slow tapering in the following 18 months. There have been no recrudescences in the last 3 years of follow-up.

Thorax 2012;67:280. doi:10.1136/thoraxjnl-2011-200573

\section{REFERENCES}

1. Katzenstein $\mathbf{A L}$, Doxtader E, Narendra S. Lymphomatoid granulomatosis: insights gained over 4 decades. Am J Surg Pathol 2010;34:e35-48.

2. Myers JL, Kurtin PJ, Katzenstein AL, et al. Lymphomatoid granulomatosis. Evidence of immunophenotypic diversity and relationship to Epstein-Barr virus infection. Am J Surg Pathol 1995;19:1300-12.

3. Lee JS, Tuder R, Lynch DA. Lymphomatoid granulomatosis: radiologic features and pathologic correlations. AJR Am J Roentgenol 2000:175:1335-9.

4. Nicholson AG, Wotherspoon AC, Diss TC, et al. Lymphomatoid granulomatosis: evidence that some cases represent Epstein-Barr virus-associated B-cell lymphoma. Histopathology 1996; d29:317-24.

5. Pittaluga $\mathbf{S}$, Wilson WH, Jaffe ES. Lymphomatoid granulomatosis. In: Swerdlow SH Campo E, Harris NL, eds. WHO Classification of Tumours of Haematopoietic and Lymphoid Tissues. Lyon: IARC, 2008:247-9. 